\title{
10 ALMO 127, VERSículo 1: ATIVISMO RELIGIOSO E ORDENAMENTOS DA SEGURANÇA EM UMA PERIFERIA de SÃo PAUlo ${ }^{1}$
}

\author{
Ana Paula Galdeano \\ Centro Brasileiro de Análise e Planejamento (CEBRAP) - São Paulo \\ São Paulo - Brasil
}

"Se o Senhor não vigiar a cidade, em vão vigia o sentinela" (José - evangélico, segurança privado e membro do Conselho de Segurança Pública)

\section{Introdução}

As igrejas de denominação pentecostal são uma entre outras modalidades de organizações civis que passaram a incorporar a questão da "violência" em suas ações e discursos, geralmente na tentativa de "salvar" ou "disputar" os jovens com o "crime" ${ }^{2}$. A literatura específica, que tem crescido desde a década de 1990 e ganhado novos contornos a partir de 2000 , mostra que as práticas das organizações religiosas são variadas. Essas envolvem rituais de exorcismo para resgatar jovens ameaçados de execução pelo tribunal do tráfico (Birman e Machado 2012); vigílias em favelas em semanas de "guerra" do tráfico e busca da santificação diretamente dirigida à questão da violência, por meio da assistência espiritual e proselitista (Mafra 1998); ou por trabalhos de prevenção e reeducação de usuários de drogas e criminosos (Zaluar 1998), muitas vezes realizados através de clínicas de recuperação de dependentes químicos 
(Machado 2013). Outras formas de mediação indicam a conversão de criminosos em evangélicos (Cortês 2007) e a conformação de "traficantes evangélicos" (Vital Cunha 2008). Há ainda convergências, não sem torções, entre o discurso religioso de inspiração evangélica e os discursos e formas de atuação do Primeiro Comando da Capital (PCC) em que "o sofrimento alimenta ainda mais a coragem", "Deus é o único juiz" e "o crime é um pecado como outro qualquer" (Biondi 2008:07). A ética evangélica, diz Biondi, confere uma singularidade ao "espírito do crime" na medida em que atravessa a existência do PCC. Tudo indica que a ética protestante se desdobra no "espírito do crime", mas também no "espírito das periferias". Quem faz, hoje, pesquisa nas periferias (sobre famílias, políticas, organizações civis ou crime) se depara inevitavelmente com as igrejas evangélicas.

Esses movimentos começaram a ser descritos pela literatura a partir da década de 1990, que foi acompanhada pelas consequências da acumulação flexível (Harvey 2012), a ampliação do terceiro setor e das ONGs e pela profusão dos evangélicos na política. Em artigo publicado em 1998, portanto há quinze anos, Mafra pontua que "Nos últimos anos, essa guerra espiritual [entre Deus e o Diabo] - que pode assumir diferentes contornos - tem recebido uma versão particularmente voltada para o drama da violência" (Mafra 1998:288). A partir da década de 2000, as pesquisas sobre religião intensificam a discussão sobre as mediações realizadas pelas igrejas evangélicas nos conflitos em torno da "violência", acompanhando, em grande medida, o aprofundamento desta noção como organizadora da fala pública sobre as periferias ${ }^{3}$.

Este artigo explora algumas relações entre ativismo religioso e "violência". Mais especificamente, discute o protagonismo político-religioso de um fiel da Igreja Universal do Reino de Deus (IURD), e da própria igreja, nos conflitos relativos à "violência". Na primeira parte do artigo, a análise está embasada na trajetória pessoal de José, tomada aqui como uma estratégia de pesquisa que opera como guia descritivo para a compreensão de processos mais amplos (Moreira 2011) ${ }^{4}$. Em seguida, apresento a etnografia de um culto da IURD Sapopemba, periferia leste de São Paulo.

Seguindo a trajetória de José, bem como as relações que estruturam sua rede social, abordo a maneira como a Teologia da Prosperidade figura como dispositivo que produz operadores privados de segurança conectados com a política pública de segurança, as políticas sociais e a política partidária. Considero que a ação social e as formas de agenciamentos podem ser compreendidas levando-se em conta as relações que esses atores estabelecem ao longo do tempo com outras organizações civis, as políticas estatais, os espaços públicos de participação e as próprias populações: prisioneiros, consumidores de crack e moradores de rua. A trajetória de José é, por isso, tomada aqui como recurso heurístico para compreender o diagrama religião / empreendedorismo / segurança (privada e pública) / política partidária / assistência, iluminando como ele se desenrola. Por outro lado, procuro explorar como os cultos da IURD, vis-à-visas redes de José, operam através de performances miméticas do poder do Estado (Das 2009) ao convidar seus fiéis a se portarem como "soldados" no 
"exército de Deus" no "resgate" de seus parentes e vizinhos. Interessa-me, nesse ponto, desvelar a noção de guerra como categoria significante que permite o nexo entre a "Guerra de combate ao crime" e a "Guerra entre Deus e o Diabo". Argumento que no enfeixamento dessas duas noções de guerra está o conceito de "guerra justa". Nas duas partes do artigo, explora-se a maneira como o ativismo evangélico na área da violência se funda a partir de formas variadas de "acordos" com o Estado, contribuindo para a correlação de projetos seculares e religiosos e o ordenamento da segurança na vida cotidiana dos moradores das periferias urbanas.

A proposta traz desafios, pois entro aqui em um campo no qual apenas muito recentemente tenho me debruçado. $O$ tema não surgiu a partir de meu interesse direto pelas mediações entre o religioso e o "combate à violência", mas, ao contrário, apareceu como um subtema, dos mais relevantes, no contexto de uma pesquisa de longa duração sobre as práticas, os discursos, as relações e os diferentes regimes de ação de organizações civis envolvidas na temática da "violência" (Galdeano 2009, 2012, 2013a e 2013b). O percurso da minha pesquisa se desenhou, grosso modo, a partir de etnografias nos Conselhos de Comunitários de Segurança Pública de São Paulo, onde foi possível acompanhar as interações cotidianas e concretas dos atores nesse espaço de participação, estendendo-se para a compreensão das conexões dessas organizações com seus contextos externos - suas redes, os significados que adquirem a partir dessas interações mais amplas, bem como suas diferentes lógicas de atuação e dinâmicas de relação (Gurza Lavalle, Castelo e Bischir 2007; Tatagiba e Blikstad 2011; Marques 2012).

Nos últimos anos, tenho pesquisado os engajamentos - redes, gramáticas, moralidades e linguagens - de um feixe diverso de organizações civis que passaram, de modo progressivo e crescente, a se definir como atuantes na temática da "violência". Tanto em São Paulo como no Rio de Janeiro, alguns estudos têm indicado a ampliação de mobilizações de organizações civis no debate e ações no combate à "violência"; movimento que teve início a partir da década de 1990, ampliando-se a partir de 2000, como assinalado. Feltran (2011a e 2011b) mostra que o contexto de "expansão do mundo do crime" denota um movimento em que atores como a escola, a família, a religião, o trabalho, a justiça, o Estado, passaram a se pensar em disputa com o "mun-

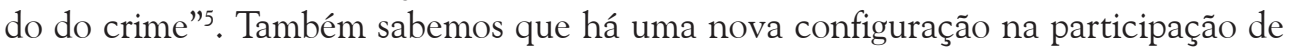
atores e organizações civis no debate público sobre a "violência" e segurança. No Rio de Janeiro despontam trabalhos sobre "redes de mães" (Vianna e Farias 2011) e oprotagonismo de familiares de vítimas de violência institucional (Birman e Leite 2004; Soares, Moura e Afonso 2009). Já há convergências analíticas em nossos debates, entre Rio e São Paulo, que apontam igualmente para o fato de que "estão em curso tanto deslocamentos de posições e mudanças nas gramáticas políticas de organizações associativas preexistentes quanto a entrada de novos grupos e personagens no espaço público" (Landim 2012:70).

Esses deslocamentos no campo do associativismo na área da "violência" não poderiam ser pensados sem levarmos em conta a "cidade como plano de referência" (Telles 
2006). Isso significa que as trajetórias e etnografias realizadas nas periferias podem ser pensadas como enfeixamentos de dinâmicas urbanas que extrapolam o caso em si, sem perder de vista a análise de processos mais gerais que revelam transformações nas últimas três ou quatro décadas das dinâmicas urbanas ${ }^{6}$. Como se sabe, as cidades e suas periferias têm sido marcadas por profundos deslocamentos nas esferas do trabalho, ação coletiva, políticas públicas e religião, ao mesmo tempo em que o contexto de violência passou a ser discutido mais enfaticamente pelos atores sociais, imersos em uma textura associativa que se tornou mais densa (Feltran 2010 e 2012; Telles 2006). Como tem sido apontado pela literatura, essas mudanças reconfiguram tipos de agenciamentos e redes (Telles 2006) ${ }^{7}$. Meu ponto de partida é que há uma diversidade de instituições e pessoas que se dedicam a diferentes modalidades de ação em um mesmo território, cujas redes, trajetórias pessoais e institucionais, formas de agenciamento, gramáticas, engajamentos e regimes de ação precisam ser compreendidos.

No cerne desta questão está a argumentação de Machado da Silva (1993 e 2004), Zaluar (1999) e Misse (1999) sobre tratar a violência urbana como uma representação ${ }^{8}$. Ou seja, como uma categoria de entendimento do senso comum que confere sentido às experiências vividas nos territórios, e que orienta instrumental e moralmente os cursos de ações individuais e coletivas, dependendo das diversas situações em pauta. Portanto, os sentidos "violência" dizem respeito a modos de compreensão da violência urbana que perpassam elementos instrumentais, cognitivos e linguísticos (Machado da Silva 2004).

Ao explicitar, empiricamente, os laços sociais que tecem um tipo específico de engajamento religioso na área da violência, pretendo abordar três aspectos das relações entre ativismo religioso e "violência". Primeiro, a maneira pela qual as mudanças operadas nas últimas décadas - a crise econômica da década de 90; o aumento do associativismo, inclusive religioso; o crescimento do setor terciário, as transformações no mundo do crime, etc. - conformam a trajetória e o engajamento civil de José, fiel da IURD e segurança privado, em direção a uma ação que contribui para o ordenamento da segurança no gerenciamento das tensões e conflitos na periferia. A doutrina da Teologia da Prosperidade é o dispositivo institucional e discursivo desta ação. Segundo, colocar em relevo as correlações, ou interfaces, entre religião, empreendedorismo, mercado da segurança, segurança pública, assistência (pública e religiosa) e política partidária, que revelam relações entre o secular e o religioso no enfrentamento da "violência". Não pretendo generalizar o argumento, ele vale para o caso estudado, embora o contexto de mudanças mais amplas que está em sua base - inclusive o conflito social contemporâneo que tem como referência central a "violência" - cruze outras correlações igualmente originais. Por fim, a partir da etnografia no culto da IURD, pretendo explorar o discurso militarizado por ela adotado que, igualmente, contribui com dispositivos político-religiosos que reforçam o ordenamento da segurança na cidade. No intuito de reforçar o argumento de que há, contemporaneamente, entrelaçamentos entre o secular e o religioso nas periferias das metrópoles, faço referências a outros trabalhos 
que indicam processos similares no Rio de Janeiro, como o caso da Assembleia de Deus dos Últimos Dias (ADUD) descrito por Machado (2013), em que o diagrama religião / segurança / assistência / política partidária também opera, assim como o caso da banda gospel do Batalhão de Operações Especiais (BOPE) analisado por Birman (2012). Para marcar meu ponto de que o caso de José e da IURD é particular no cenário de São Paulo, mobilizo uma etnografia sobre a atuação do emaranhado de atores que compõem o cenário da "cracolândia" paulistana (Rui 2012) e a atuação específica do Projeto Cristolândia, encampado pela Igreja Batista na mesma região (Fromm 2014).

\section{Correlações e interfaces: diagrama religião, empreendedorismo, segurança, política partidária e assistência}

Conheci José em 2006, em pesquisa de campo realizada nos encontros do Conselho Comunitário de Segurança Pública de Sapopemba, zona leste de São Paulo. Ele era vice-presidente do conselho, também dono da firma de segurança privada Águia Forte, nome que revela os triunfos da salvação espiritual operada no decorrer de sua trajetória evangélica. Fazendo pesquisa naquele espaço, já era possível identificar que a configuração das organizações civis mobilizadas nos assuntos de "violência" e segurança nos anos 2000 já diferia muito da composição da sociedade civil que frequentava o espaço em meados da década de 1980, quando os conselhos foram instituídos em várias cidades do estado de São Paulo, inclusive na capital ${ }^{9}$. Além dos personagens tradicionais (delegados, policiais civis e militares, comerciantes e representantes de clubes de serviço), figuravam como participantes desse espaço líderes de associações de bairro, diretores de escola, militantes de direitos humanos, representantes do Conselho Tutelar; pessoas das mais diferentes orientações políticas e religiosas, além de um mix entre algumas dessas posições. José era um desses personagens que escapa a qualquer tentativa de enquadramento através de um único atributo. A performance dele é, a um só tempo, ligada ao mercado da segurança privada, à segurança pública e à proposta salvadora junto às populações "sofredoras", das quais ele mesmo foi "resgatado".

Na década de 1980, então com 14 anos, José frequentava a favela, fumava maconha e cheirava cola com seus amigos e um traficante. Nessa época, os bandidos locais faziam "mansão", roubavam em bairros nobres, como o Morumbi. A execução de um bandido foi o evento que abriu caminho para que ele deixasse esse mundo, assumindo o trabalho. Na leitura do passado a partir do presente, José atribui a passagem pelo "mundo das drogas" como um aprendizado, parte da "faculdade da vida" que havia sido traçada por Deus para lhe colocar diante da privação e poder atuar sobre ela.

Ele trabalhou com o pai, migrante de Pernambuco, em um bar e, em outro turno, era porteiro no centro da cidade. O pai morreu, ele assumiu o bar e cuidou da mãe enferma. Tornou-se evangélico em 1993, após a morte da mãe. Foi quando decidiu transformar o bar em uma bomboniere, porque, segundo ele, há um paradoxo entre 
servir a Deus e vender bebida alcoólica: "Todo dono de bar, dono de boteco, todos são ignorantes, gostam de falar alto, gostam de andar só de bermuda, sem camisa, por quê? Porque é um verdadeiro ignorante, não tem estudo, não tem nada"10. Tinha uma situação financeira estável quando chegou na IURD aos 18 anos, dois carros e poupança no banco. Em 1996, a bomboniere faliu e a vida despencou. Perdeu tudo o que tinha, inclusive o respeito dos irmãos, e morou um mês na rua. "Dentro da igreja eu dobrava o joelho e pedia pra Deus: 'me tira, eu não quero mais viver"'. O que segurou a vida foram os planos com a namorada Marlene, hoje sua esposa, e a promessa de prosperidade da IURD.

Bem conhecida pelos estudiosos da religião, a Universal é uma igreja surgida na chamada terceira onda pentecostal no Brasil, denominada de neopentecostal, vertente que mais cresceu ao longo dos anos 80 e 90 (Mariano 1996; Almeida 2009). Criada em 1977 no Rio de Janeiro, a IURD participa de partidos políticos, apresenta pouco traço de seita, faz uso dos meios de comunicação no rádio e televisão e de equipamentos tecnológicos em seus cultos. São características compartilhadas pelas demais igrejas neopentecostais que surgiram a partir da segunda metade dos anos 70: a Internacional da Graça de Deus, fundada em 1980 no Rio de Janeiro; a Comunidade Evangélica Sara Nossa Terra, inaugurada em Goiás, em 1976; e a Renascer em Cristo, instituída em São Paulo, em 1986. A Teologia da Prosperidade, adotada por estas igrejas, foi uma das responsáveis pelo crescimento das igrejas neopentecostais, reordenando os padrões de comportamento dos fiéis com a sociedade (Mariano 1996:26). As doutrinas e os ritos desta teologia prometem recompensas: prosperidade material e redenção da pobreza, saúde, fim do sofrimento e triunfo sobre o Diabo. José se apegou a essa doutrina para fazer seu propósito com Deus quando estava desempregado e, Marlene, grávida. Os relatos sobre essa fase são de sofrimento e privação material: noites dormidas na rua, fome e humilhação. Emocionado, ele conta que subia em um barranco e "punha o rosto no pó da terra e ficava lá clamando a Deus".

Seguiu participando dos cultos realizados na IURD Brás, localizada em região de grande fluxo urbano, a Av. Celso Garcia, uma grande avenida da zona leste de São Paulo que faz a ligação com o centro da cidade ${ }^{11}$. José se integrou ao grupo do pastor Atílio, que realizava evangelização e trabalhos de assistência aos presos. A evangelização foi realizada entre 1997 e 2001, e consistiu na pregação da palavra e no socorro espiritual em delegacias, penitenciárias e CDPs (Centros de Detenção Provisórios). As atividades de salvação da IURD eram possibilitadas pela bancada evangélica que mediava as relações entre os pregadores e os equipamentos de segurança, de um lado, e os pregadores e os presos de outro. A bancada evangélica exerceu um importante campo de mediação para as articulações entre a esfera política e a esfera religiosa, já que a entrada nas delegacias, presídios e CDPs envolve trâmites administrativos junto às instituições estatais. Os legisladores do PFL (Partido da Frente Liberal) e PP (Partido Progressista) se encarregavam dos contatos pessoais e da emissão de documentos para a realização da pregação. 
Esse modo de atuação revela as formas renovadas de ativismo político, social e moral dos evangélicos. Como mencionei, um dos traços marcantes das igrejas neopentecostais é sua inserção direta na esfera política. A bancada evangélica no Brasil teve inicio com a restituição das eleições direitas em 1982, iniciando a progressiva atuação de parlamentares de confissão evangélica no Congresso, inaugurando um fenômeno novo no período que Pierucci (1996) chamou de "ativismo político religioso de grupos protestantes na esfera pública política". O que se verifica de lá para cá é o desdobramento da atuação partidária e parlamentar, e a emergência de um novo tipo de ativismo. A participação na Constituinte foi apenas o início da disseminação do pentecostalismo na política brasileira, a partir da qual os evangélicos ampliaram o âmbito religioso, transformando partidos e parlamentos em "instrumentos para a realização da obra de Deus" (Almeida 2009). O caso de José indica que o ativismo político religioso abriu espaço para um ativismo evangélico na área da "violência", em que deputados estaduais e vereadores ligados à bancada evangélica se valem de suas posições no legislativo para mediar as relações entre os obreiros e os equipamentos de segurança pública ${ }^{12}$. Cabe dizer que dos 55 vereadores eleitos para ocupar mandatos em 2013 na cidade de São Paulo, 11 são evangélicos ${ }^{13}$ e dois são ex-policiais da ROTA (Rondas Ostensivas Tobias de Aguiar) ${ }^{14}$. O blog do presbiteriano João Cruzué, entretanto, contabiliza 12 evangélicos, contando que o vereador Conte Lopes pertence à Congregação Cristã no Brasil ${ }^{15}$. Entre os vereadores da bancada evangélica, a maioria é de bispos licenciados da IURD.

O trabalho missionário e de assistência da IURD envolve, para além dos presos, os jovens internos que cumprem medida de internação. A página "IURD na Fundação Casa"16 dá destaque para o bispo Atílio (provavelmente, o mesmo pastor que José acompanhava nas evangelizações), vereador pela quarta vez consecutiva em São Paulo (2000, 2004, 2008 e 2012), atualmente do PRB (Partido Republicano Brasileiro). As atividades na Fundação passam por batismo de internos ("rituais de confissão" de pessoas que "deixam o velho modo de vida" e passam a viver em "novidade de vida"), entrega de jornais nas filas para a entrada nas unidades, almoços para as famílias, atividades esportivas e assistenciais. Desde o final da década de 1990, a IURD tem uma ampla oferta de serviços assistenciais e uma ação social filantrópica empreendedora que envolve discussões sobre o terceiro setor, a promoção de ações culturais de lazer e o combate ao uso drogas, entre outras (Rosas 2013). Como mostra a autora, as ações filantrópicas e caritativas da IURD contam com forte apoio da base política dos evangélicos no Congresso Nacional, e se estendem para outros países da América Latina e da África. As mensagens religiosas, no Brasil e na rede assistencial da IURD no globo, cedem lugar aos discursos de paz, meio ambiente e direitos humanos. Entretanto, o discurso de José destoa dessa estratégia pós-moderna de assistência iurdiana: o discurso dos direitos humanos é praticamente nulo, não fosse a aceitação da cartografia discursiva dominante que condena o "papo de direitos humanos" e o apóia "práticas mais enérgicas" por parte dos policiais. Os agenciamentos e redes de 
José configuram uma forte ênfase na atuação do Diabo na vida moradores envolvidos no crime e nas drogas, e um direcionamento voltado para a segurança pública, de um lado, e o mercado da segurança, de outro.

A experiência de evangelização mediada por políticos evangélicos conferiu sentido à vida pregressa de José, que foi interpretada como plano divino necessário para a conversão de bandidos. Também, a partir do contato com a dinâmica das delegacias e das prisões, foi "revelada" a sua missão espiritual e profissional: atuar no combate à "violência". Embora a sociabilidade na IURD seja menos "congregacional" e mais verticalizada, fomentando vínculos fortes entre a multidão e o pregador (Almeida 2009), no caso de José, a rede iurdiana teve sucesso em estabelecer mecanismos de ajuda mútua entre "os irmãos", fomentando a autoestima e expandindo o espírito empreendedor. Foi ancorado exatamente nesses preceitos de valorização da pessoa e no empreendedorismo que José conquistou a salvação individual e se voltou para salvação de presos, usuários de crack e moradores de rua (embora seu discurso estivesse menos organizado pela busca por justiça social como valor universal, como fazem os católicos). A mediação da IURD com os equipamentos de segurança possibilitou troca de informações e contatos pessoais que culminaram na saída da crise financeira vivida nos anos 90, mediante a abertura da empresa de segurança privada Águia Forte.

As mudanças na economia e o fim do sofrimento e da "depressão" se expressam na passagem de um período de crise para um período de "abundância", em que José se torna empregador no terciário e pequeno empresário do ramo da segurança privada. Isso, já nos anos 2000, no contexto de "expansão do mundo do crime". Em 2005, a empresa dele vigiava 25 estabelecimentos comerciais na Avenida Sapopemba, e empregava seis seguranças. "Eles não ganham mal, eles ganham bem. São seis pais de família (...). E lá atrás eu passava fome, não tinha nenhum emprego. Hoje, Deus me abençoou, me deu do bom e do melhor." Em 2011, já eram 30 lojas, e José decidiu diminuir a folha de pagamento. Com o dinheiro que sobrou do "bem bolado", financiou um carro.

Os vínculos comunitários também prosperaram. Ele passou a frequentar o Conselho de Segurança do bairro, tornando-se vice-presidente por dois mandatos, estabelecendo relações com políticos, conselheiros tutelares e policiais da área, ampliando sua rede pessoal e prestígio. Mas esse também foi um período de ameaças. A empresa de segurança tirou os "bicos" de alguns policiais que trabalhavam na região. José sofreu ameaças de morte por telefone e chegou a ser intimidado por um policial que foi até a sua casa armado. Com a proteção do delegado de polícia da delegacia local, a vida seguiu sem que as ameaças fossem constantes, tampouco consumadas.

Como segurança privado, José protege o comércio local dos furtos e roubos. Como evangelizador de presos, ele reconhece o "chamado de Deus" para salvação e a vocação para libertar os desgarrados da "opressão". Em 2011, motivado pelos conflitos no bairro, ele decide ajudar a "montar uma igreja, ganhar almas pra Jesus, 
tirar o povo da rua, tirar o povo das drogas". Ele apoiou financeiramente a criação do Ministério Vinho Novo, que contou com o apoio espiritual da IURD. Com laços sociais mais diversificados, ele passou a realizar a mediação de conflitos comunitários não mais nos presídios e nas carceragens, mas na periferia de Sapopemba e em outros territórios periféricos, acionando, para tanto, sua rede pessoal e as instituições locais.

Na Praça da Sé, ele distribuiu sopão para os moradores de rua durante três meses, uma vez por semana, em um esquema familiar que contava com a mulher, a irmã, a sobrinha e o noivo dela. Parou quando a tentativa de conversão de Carlão, um morador de rua de 45 anos, não deu certo. José decidiu ajudá-lo mediante o trato de que o homem largaria a cachaça. Alugou uma casa em Sapopemba, comprou móveis usados, o levou para cortar o cabelo e fazer a barba, deu "banho de loja" e arrumou emprego em um estacionamento. "Você tá trabalhando aqui, não é obrigado a nada; você tem que parar de beber, não vai beber; tua vida mudou é outra coisa, você vai pra igreja comigo; você não é obrigado a ir para igreja, mas você vai ter que mudar de vida". Carlão não era "obrigado a nada", mas, por não se adequar às práticas da intervenção "salvadora", a benesse claudicou. Carlão começou a beber e a criar problemas na vizinhança, parou de tomar banho, perdeu a chave de casa várias vezes. Foi quando José avaliou que a oportunidade dada não fora aproveitada. Tirou a casa e o emprego do homem, que voltou para a rua e cujo paradeiro não se sabe.

José também mediou a adoção de três meninas de 8,6 e 5 anos, filhas de uma mulher prostituta e usuária de crack. As meninas eram vistas constantemente na rua e ele decidiu levá-las para casa até encontrar um caminho mais definitivo. Ligou para a Polícia Militar e Delegacia de Polícia e explicou que essas crianças tinham sido resgatadas por ele, de modo a evitar que algum vizinho o denunciasse como corruptor. Também acionou o Conselho Tutelar, que tentou fortalecer o vínculo familiar, mas, a partir de sucessivas tentativas, as meninas permaneceram na rua. Sem sucesso, os conselheiros entraram com um processo na Vara da Infância e Juventude para tirar a guarda da mãe. Durante o período em que o processo corria, José cuidou das meninas. Comprou cadernos, deu roupas e brinquedos. As meninas foram rapidamente adotadas por um casal do Rio de Janeiro. O pai adotivo é capitão da Marinha e a mãe é doutora em Psicologia.

Para além dos propósitos da salvação que esses dois eventos sugerem, possibilitados pela prosperidade que José alcança a partir de sua filiação na Igreja Universal do Reino de Deus e da incorporação da doutrina da Teologia da Prosperidade, chama a atenção as redes acionadas para "libertar" as pessoas do "coisa ruim". Especialmente no caso das três irmãs, todos os vínculos acionados foram possibilitados pelos contatos que José estabeleceu no Conselho Comunitário de Segurança Pública: a Polícia Militar, a Polícia Civil e o Conselho Tutelar. São esses vínculos, expandidos ao longo dos anos 2000, e possibilitados pela participação dele nos assuntos da segurança, que permitem realizar a mediação dos conflitos comunitários e disputar a legitimidade com o "crime", representado aqui pelo crack. 
Engajar-se significa salvar os indivíduos, mas também solicitar à Secretaria de Segurança Pública que coloque a "Rota na Rua", chavão propagado há tempos por Paulo Maluf. Em meados de 2011, a Avenida Sapopemba teve, segundo José, o primeiro grande assalto a banco, quando 10 homens armados levaram grande quantia em dinheiro. $\mathrm{O}$ assalto foi atribuído ao PCC pelo porte das armas de fogo usadas. Os participantes do Conselho de Segurança pediram que a ROTA e a Força Tática circulassem com mais intensidade pelo bairro.

A trajetória de José chama a atenção para a rede de relações em que se cruzam a religião, o mercado da segurança privada, o empreendedorismo, a segurança pública, a política partidária e os equipamentos de assistência e justiça do Estado. O que liga essas dimensões, ou melhor, o que a trajetória de José permite dizer, é que sua ação social, política e moral foi constituída a partir de um referencial religioso que ampliou a sua rede local. Se na década de 1990 o vínculo de José estava adstrito à sua posição de fiel e missionário da IURD, em 2000 as relações se ampliam em direção ao ordenamento de um ativismo religioso na área da violência no espaço da periferia, além do mercado de segurança privada. Misturam-se, nesse novo contexto, o discurso empreendedor, o discurso religioso e o discurso da segurança, e a combinação de projetos seculares e religiosos.

\section{O dia do resgate: a "guerra justa" como enfeixamento entre a "guerra de combate ao crime" e a "guerra entre Deus e o Diabo"}

Durante 2011, acompanhei José e sua família em alguns cultos da IURD Sapopemba. $O$ templo se destina a cerca de 700 e 800 fiéis, e se localiza nas proximidades da Avenida Anhaia Melo, que nos últimos anos tem sido objeto de uma grande reforma urbana para acomodar a estrutura do monotrilho que recortará toda extensão da avenida. Nos cultos dominicais, a dinâmica consiste na pregação da palavra, na qual os principais temas do pastor são a "libertação da opressão" de vidas dominadas pelo Diabo, a proteção de famílias "deprimidas" pela violência, furtos e assaltos, além da prosperidade econômica. Em alguns momentos, o culto era acompanhado de músicas, orações e bênçãos dos 15 obreiros vestidos de azul, que se posicionavam ao redor do salão.

O culto de 25 de setembro de 2011 chamou particular atenção. Naquele dia, o pastor vestia uma jaqueta camuflada. Durante a pregação, um telão foi baixado nas proximidades do púlpito. A cena era de dois adolescentes parados em uma esquina, uma sugestiva encruzilhada, onde os meninos conversavam sobre o valor pago na moto que aparecia na imagem. Repentinamente, surgem dois carros em alta velocidade, que se chocam violentamente. A tela esfumaça, dando a impressão que os adolescentes foram atingidos pelo acidente. A partir desta cena, o pastor refletiu sobre a necessidade do "desapego material", a importância da conquista dos bens materiais ligada à concepção de que há sempre uma "ação e reação", conectando esses fatos, ao final, com o dízimo. A cena da colisão estava apenas de forma subliminar ligada à "violência urbana". 
O propósito da vestimenta camuflada, entretanto, ficou claro apenas no final do culto, quando o pastor distribuiu um folheto, também camuflado, onde se lia: "Dia 25/09, Domingo do resgate. Eu faço parte deste Exército". Logo abaixo, havia espaços em branco após as palavras "resgatador" e "resgatado", onde cada fiel deveria escrever os nomes dos salvadores e dos que seriam salvos. Nesse panfleto a linguagem militar é a acionada, indicando "acordos" entre o Estado e as comunidades, e como o Estado está presente nas performances miméticas do poder onde a autoridade é invocada.

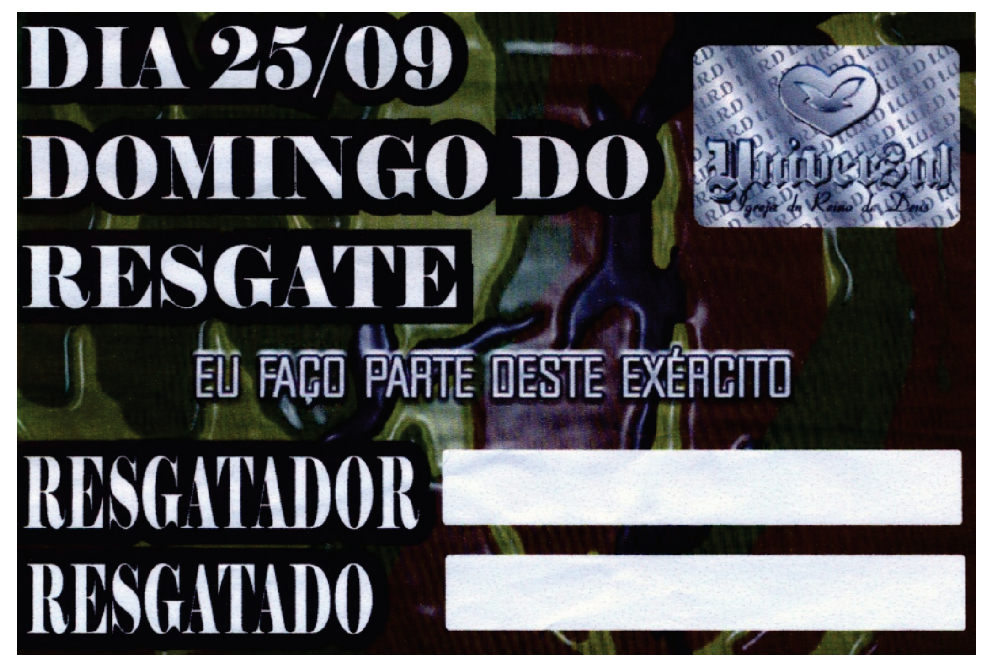

Panfleto coletado em pesquisa de campo na IURD Sapopemba (2011)

Veena Das (2007) trabalhou os sentidos desses "acordos" ao sublinhar que seu entendimento de comunidade não é oposto ao de Estado. A concepção de "acordos" é entendida não como concordância quanto à linguagem, mas como ideias e crenças compartilhadas (Das 1999:38). Especialmente no capítulo The signature of the State: the paradoxof illegibility, Das (2007) sustenta que o Estado não é apenas uma entidade racional burocrática. De fato, ele está presente nas estruturas que regulam a sociedade, nas regras cotidianas, nas regulações que são corporificadas nas leis e aplicadas pelas instituições, mas seu poder também é atualizado no dia a dia das pessoas por meio de performances e representações miméticas. $\mathrm{O}$ Estado adquire presença na vida das comunidades por meio de práticas locais, que a autora chama de mágicas, as quais estão aliadas ao poder. Não se trata, aqui, de simples performances teatrais das práticas de Estado,como descrito por Taussig em sua análise sobre os funerais (1997). As práticas mágicas não são transparentes, implicam em consequências reais e envolvem pessoas em situações de vulnerabilidade. 
A ideia de assinatura remete tanto ao caráter racional do Estado quanto às performances miméticas do poder, em que a autoridade do Estado é invocada. Das mostra que a assinatura do Estado é fraudada em outras estruturas e cadeias de significados que envolvem as relações entre funcionários de Estado e as comunidades, e mesmo na busca por justiça entre as pessoas que vivem em situação de violência. A proposta da autora é compreender como as práticas cotidianas indicam a presença do Estado, este que se move entre a presença de práticas racionais e práticas mágicas. Uma das consequências desse enunciado é a proposta metodológica da autora, para quem o estudo do Estado exige deslocar o olhar de lugares óbvios em que se espera o poder, para procurá-lo nas margens da vida ordinária.

Tomando de empréstimo os insights da autora, interessa aqui sublinhar que há uma correlação mimética entre a ação (social, política e moral) da IURD e a ação militarizada das instituições de segurança, que indica práticas reais de relações entre o projeto secular da segurança e o projeto religioso iurdiano. $O$ pastor convoca "soldados" para o "exército de Deus", nessa "guerra" cuja finalidade é o "resgate" das almas. Esse tipo de prática mimética cola em territórios periféricos em contextos de "expansão do mundo do crime", onde as noções de "Guerra contra as drogas", "crack", "crime" e "Diabo" são frequentes. Tal prática faz sentido também para José, "soldado" da segurança privada e no "resgate" de presos, moradores de rua, consumidores de crack e suas famílias, uma vez que opera efetivamente entre os projetos seculares (de segurança e assistência) e o projeto religioso da IURD a partir de suas redes de relações institucionais e pessoais, descritas anteriormente. Faz sentido ainda para os legisladores evangélicos que frequentemente transitam entre os assuntos teológicos e as pautas de assistência e segurança pública.

Com efeito, a adoção de um discurso militar não é algo novo no cristianismo, nem mesmo algo específico do contexto atual de "violência urbana". Entretanto, como afirma Birman (2012), estamos diante de novas formas de entrelaçamento e presença religiosa (sobretudo evangélica) na esfera pública. Nesse sentido, "O quadro de alianças entre instituições tem se modificado enormemente com a consolidação pentecostal na esfera pública e outras articulações e projetos religiosos e seculares não cessam de emergir" (Birman 2012:211). A construção social e histórica da "violência" e do "crime" como um problema público recente, noções que operam discursivamente para caracterizar as periferias urbanas, tem contribuído para que essas noções se encontrem vinculadas a projetos secularistas, projetos religiosos e que relacionam o secular e o religioso no enfretamento da questão. Como afirma a autora:

A categoria 'violência' aumentou a sua abrangência e seus sentidos e se impôs como uma das justificativas centrais para reordenações necessárias dos espaços da cidade, desdobrando-se em políticas de repressão, de controle, de vigilância e também de medidas sócio-morais dos sujeitos que seriam seus alvos preferenciais. As mediações promovidas pelos atores 
religiosos no tratamento do 'problema da violência' se desenvolveram ao longo desse processo e integraram os debates e também alguns dispositivos engendrados para governar a cidade, seus conflitos e suas populações (Birman 2012:211).

Visando compreender as performances miméticas, o poder de evocação da autoridade de Estado e as relações entre o secular e o religioso, sugeridos não apenas pelo panfleto iurdiano, mas também pelas redes e fluxos de José, interessa analisar os enfeixamentos que dão sentido às noções de "Guerra de combate ao crime" e "Guerra entre Deus e o Diabo". A ideia de "guerra", segundo Foucault (2002), é constitutiva da passagem da sociedade disciplinar para a sociedade de controle. Nesse processo, que se deu entre meados do século XVIII e o século XIX, entra em cena uma série de mecanismos regulamentadores sobre as populações e, mais propriamente, em meados do século XIX, as guerras ativam o tema do racismo, que dá lugar à guerra das raças. Para Foucault (2002), no sistema biopolítico, o racismo, entendido não apenas em seu domínio étnico, mas também dirigido aos doentes mentais e criminosos, aparece justificando o fato de matarmos aqueles cuja vida deveríamos proteger, "fazer viver". As tecnologias de bio-regulamentação do Estado estendem-se às diversas formas de racismo, nas quais o que está em pauta é a correlação, a justaposição, no termo do autor, entre o poder soberano do Estado e o biopoder ${ }^{17}$. Levando-se em conta o empreendimento genealógico de compreender os processos históricos do poder, pode-se argumentar que a "guerra do combate ao crime" reativa o poder soberano de "fazer morrer e deixar viver".

A importância da noção de guerra para a discussão da soberania foi recentemente retomada por Hardt e Negri (2001), que utilizam o conceito de "guerra justa" para explicar as implicações dos novos mecanismos regulamentadores da biopolítica na configuração das relações globais de poder e na igualmente nova soberania global. Os autores enfatizam a continuidade entre o poder soberano, o poder disciplinar e a biopolítica por meio do renascimento do direito imperial de bellum justum. O conceito de "guerra justa", que remonta às antigas ordens imperiais e bíblicas, começou a reaparecer como narrativa central das discussões políticas, baseada "na ideia de que, quando um Estado se vê diante de uma ameaça de agressão que pode pôr em risco sua integralidade territorial ou sua independência política, tem um jus ad bellum (direito de ir à guerra)" (Hardt e Negri 2001:30). Duas características tradicionais, argumentam os autores, reaparecem no mundo pós-moderno: a ação policial é reduzida ao status de guerra, e o conflito é, ao mesmo tempo, sacralizado, uma vez que no plano da legitimidade o poder emana da ética e da moral, através da celebração da luta. O conceito de "guerra justa", entretanto, não apenas retoma traços medievais, mas apresenta inovações fundamentais. Dois elementos distintos combinam-se, estão correlacionados e entrelaçados: primeiro, a legitimidade do aparelho militar desde que eticamente fundamentado; segundo, a conquista da ordem e da paz. 
Nessa perspectiva, a "guerra justa" está na interface entre as rotineiras repressões policiais, próprias dessa noção de guerra, e a construção da imagem do inimigo que ameaça totalmente a ordem ética e a paz. A construção do inimigo é também importante para Leite $(2012,2013)$, para quem a "metáfora da guerra" permite mobilizar e justificar políticas de segurança pública que tomam as favelas como inimigas virtuais e reais. Chegamos, assim, no ponto de perguntar sobre o processo de produção e circulação do discurso do "inimigo", bem como de questionar sobre as organizações produtoras desse mesmo discurso.

A resposta de Hardt e Negri caminha para a explicação de um paradigma de construção de normas e produção de legitimidade espalhadas pelo espaço mundial. Figuram nesse terreno as organizações do poder central internacional, nacional e local (ONU, Estados Nacionais, ONGs, indústrias da comunicação, etc.), que se assentam nos valores de paz, equilíbrio e fim dos conflitos. Ainda que os autores não trabalhem diretamente sobre o papel das igrejas neopentecostais nesse processo, trata-se de pensar a "variedade de entidades, incluindo os meios de comunicação e organizações religiosas (...) e [as] chamadas organizações não-governamentais (ONGs)" (Hardt e Negri 2001:54), cujas instituições exemplares são organizações internacionais como a Anistia Internacional e o Médico Sem Fronteiras, além de uma diversidade de ONGs humanitárias que figuram como poderosas armas de paz da nova ordem mundial, por meio de campanhas de caridade e assistência. "Essas ONGs movem 'guerras justas' sem armas, sem violência, sem fronteiras” (Hardt e Negri 2001:55). Os regimes de ação que as sustentam, e que circulam, definem o inimigo como privação e como pecado.

Se para a "Guerra contra o crime" importa definir um "inimigo" - traficantes, consumidores de crack, moradores de rua -, as igrejas neopentecostais identificam o "inimigo" no Diabo, que, por sua vez, está frequentemente encarnado no espírito dessas mesmas populações. Embora os dados empíricos da pesquisa apresentada neste artigo permitam pensar os dispositivos político-religiosos da IURD no plano das periferias da cidade de São Paulo, cabe também registrar que as igrejas midiáticas estão preocupadas com a constituição do cristianismo globalizado nas periferias do mundo (Mafra 2012). Alia-se a isso, a preocupação já comentada em torno dos discursos de paz e direitos humanos da IURD, que se consolidam através de sua rede empreendedora e assistencial (Rosas 2013).

Minha proposição é que a obra de Hardt e Negri, Império (2001), aponta pistas importantes para a compreensão das correlações entre "Guerra de combate ao crime" e "Guerra entre Deus e o Diabo" ao indicar a repressão e a sacralização como elementos constitutivos das novas relações que atuam nos mecanismos de regulamentação das populações, sejam eles local ou global. Ambas articulam territórios e populações, produzem subjetividades e relações sociais. Trata-se de dar atenção aos nexos imateriais da linguagem e do simbólico que são produzidos por meio de tecnologias de comunicação e imagem. Se considerarmos que a preocupação dos autores está, entre outras coisas, nos diferentes tipos de comunicação que organizam um movimento da 
soberania mundial, parece ser plausível afirmar que a IURD, por meio de seu arsenal empreendedor e assistencial no globo, mas também nas prisões, na política partidária, nos conselhos, nas empresas de segurança, cumpre um papel na produção do imaginário que é imanente às relações sociais e produtivas.

A "Guerra entre Deus e o Diabo" trata de uma intervenção moral e espiritual que está voltada para a "paz", por meio do resgate de almas. A "Guerra de combate ao crime" tem, do mesmo modo, um componente moral na medida em que a repressão das organizações envolvidas na venda de drogas "pode não ser tão importante como criminalizar suas atividades e administrar alarmes sociais sobre sua existência para facilitar o controle" (Hardt e Negri 2001:56). Nesse diagrama, os discursos da paz interna e paz espiritual, por meio das "armas" e da "palavra", são tão importantes quando a noção de guerra.

\section{Considerações finais: sobre ativismos religiosos e ordenamentos da segurança nas periferias de São Paulo e do Rio de Janeiro}

A noção de "guerra justa" que remonta à tradição bíblica forja contemporaneamente uma rede de instituições muito heterogêneas, cujas fronteiras territoriais ora estão aparentes, ora são pouco claras, mas que articula novas interações sociais, interseções institucionais, intervenções morais e correlações as quais é possível acessar, ainda que parcialmente. Como dito anteriormente, não pretendo generalizar as correlações encontradas no caso de José para todas as formas de ativismo religioso na área da "violência". Entretanto, o conflito social contemporâneo, que tem na "violência" e no "crime" a sua referência central, fornece, como a bibliografia disponível tem mostrado, formas variadas de protagonismo político-religioso nas mediações de conflitos nas periferias.

As redes e os discursos de José mostram que as mudanças nas esferas religiosa, política, econômica e social contribuem em direção a um tipo de ativismo religioso que combina religião, empreendedorismo, segurança (privada e pública), política partidária e assistência no gerenciamento das tensões e conflitos nas periferias. A doutrina da Teologia da Prosperidade é o dispositivo desta ação no contexto de "expansão do mundo do crime” em São Paulo. O Salmo 127, versículo 1, ditado por José em entrevista, sintetiza a correlação que pretendi colocar em evidência: "Se o Senhor não vigiar a cidade, em vão vigia o sentinela".

Quando afirmo que tais correlações são particulares ao caso estudado, tenho em mente que o "resgate" operado pelas diferentes igrejas evangélicas pode mobilizar outras organizações e rituais, não necessariamente aquelas que identifiquei na pesquisa com José e a IURD. Do mesmo modo, algumas organizações que compõem o diagrama explicitado na primeira parte do artigo podem estar parcialmente articuladas. É possível que algumas correlações se repitam, enquanto outras podem perfeitamente não compor o diagrama de outras modalidades de ativismo evangélico na área da 
"violência”. A literatura disponível contribui para lançar luz sobre a hipótese de que é altamente provável que organizações particulares, discursos e práticas se cruzam de uma forma diferente em alguns outros casos, tanto em São Paulo como no Rio de Janeiro, mas ainda giram em torno de noções de religião, segurança, mimetismo, violência e relações entre projetos seculares e religiosos. Certamente, não se pode deixar de levar em consideração que essas duas cidades representam contextos bastante diferentes principalmente em relação à organização do "mundo do crime". Trata-se de "mundos do crime" bastante distintos, principalmente no que tange à prática da violência física, ainda que suas representações mais genéricas se assentem no narcotráfico varejista que se desenrola nas favelas e periferias. É importante considerar, ainda, que a constituição e desenvolvimento das políticas de segurança pública nesses dois estados se desenvolveram de modos particulares e distintos. Portanto, a bibliografia deve ser mobilizada com cuidado, pois essas diferenças relativas ao "mundo do crime" e às políticas de segurança, em cada contexto, têm impactos significativos nessas articulações.

No caso de São Paulo, o trabalho de Taniele Rui (2012) mostra que o território itinerante da "cracolândia" paulistana, no centro da capital, se constitui a partir da entrada recente do crack na cidade, que, segundo os registros jornalísticos, se deu a partir da década de 1990. Contemporaneamente, tal território envolve conflitos sociais diversos e passou a ser alvo de interações heterogêneas e múltiplas: intervenção de organizações civis diversas como ONGs e igrejas; políticas estatais (assistências, urbanas, repressivas) e criminais (incluindo as ações do Primeiro Comando da Capital). Embora o foco analítico do trabalho não seja os agentes de evangelização e as igrejas, a etnografia da autora permite notar, claramente, que os usuários de crack estão envolvidos em engajamentos, gestões e interações em projetos, a um só tempo, seculares e religiosos. A "cracolândia" é um espaço público,

(...) para onde migram (...) centenas de usuários, traficantes, jornalistas, pesquisadores, policiais, instituições religiosas, assistenciais e serviços médicos. Também para esse espaço, voltam-se interesses políticos e imobiliários, repressivos e humanitários, compondo uma dinâmica caótica, de muito difícil compreensão (Rui 2013a:32).

As ações desenvolvidas nesse território passam, por exemplo, pela política de tolerância zero, como o caso do Projeto Nova Luz (Rui 2012); operações policiais, tais como a Operação Sufoco (Rui 2013b) até o Projeto Cristolândia, conduzido pela Igreja Batista, que foi analisada por Deborah Fromm (2014), um dos poucos trabalhos sobre a atuação de evangélicos na assistência, evangelização e conversão de usuários de drogas. A etnografia realizada pela autora na sede da Missão Batista Cristolândia, situada na região da "cracolândia", permite notar que as ações batistas diferem muito daquelas conduzidas pelos iurdianos. A Igreja Batista rejeita recursos públicos e não atua no campo político partidário, embora também combata o inimigo (o Diabo) 
encarnado na vida de usuários de drogas, prostituas e bandidos, e apresente algumas performances teatrais em seus cultos que recorrem a símbolos militares ${ }^{18}$. Arisco sugerir, para investigações futuras, que a relação entre o secular e o religioso se manifesta na IURD de forma mais intensa do que opera na Igreja Batista, embora minha distância desse campo não me permita afirmar que os batistas empenhem projetos religiosos contrários à secularização. De todo modo, em ambos os casos, nos dispositivos estatais e nos dispositivos religiosos, trata-se do manejo de territórios e populações, por meio da repressão, da disciplina, da educação dos mesmos sujeitos indesejáveis. O inimigo da segurança pública, sujeitos frequentemente matáveis nessa perspectiva, são os mesmos sujeitos que devem ser civilizados quando o inimigo de Deus é extirpado, nos termos religiosos.

Entretanto, como observou Birman (2012) para o caso do Rio de Janeiro - e creio que no caso da IURD de São Paulo se possa operar com a mesma linha analítica - , a modalidade de tratamento para o inimigo interno, que a primeira vista é acionada exclusivamente pela segurança pública, e o tratamento para aqueles que se deve civilizar, por meio das ações das organizações religiosas e civis, estão mais embaralhados do se pode supor. A força do mimetismo de Estado, no caso da IURD e de José, se coloca justamente porque as fronteiras entre o secular e o religioso estão nitidamente borradas. Não se trata apenas de simples performances teatrais. Seguindo redes e grupos específicos, é possível notar que algumas formas de tratamento estabelecem correlações efetivas entre o político e o religioso, como é o caso também da banda gospel do Bope (Batalhão de Operações Especiais) analisada por Birman (2012), composta por membros do Caveiras de Cristo e policiais evangélicos atuantes no Borel, que, com a Bíblia na mão direita e o emblema da caveira no ombro esquerdo, congregam no mesmo ator símbolos do poder religioso e militar. No caso de São Paulo, para além da IURD, a atuação das Comunidades Terapêuticas que recebem recursos do estado parece anunciar um campo importante de articulações entre o Estado e a religião, ainda pouco explorado pela literatura como aponta Fromm (2014).

No contexto de "pacificação" inaugurada pelas Unidades de Polícia Pacificadoras (UPPs) no Rio de Janeiro, tais articulações e embaralhamentos têm se mostrado, ao menos no registro da literatura, mais recorrentes. A análise de Carly Machado (2013) mostra a articulação entre a Assembleia de Deus dos Últimos Dias (ADUD) e a UPP do Turano, na Baixada Fluminense. A ADUD oferece apoio à política de "pacificação" através de parcerias com a UPP, que encaminha dependentes químicos para sua clínica de recuperação, o Instituto Vida Renovada. A autora argumenta que a "ADUD faz convergir a figura do 'drogado' com a do 'bandido', oferecendo recuperação ao corpo e à alma, e ressocialização ao cidadão perdido no crime e no pecado" (Machado 2013:3). As práticas da ADUD estão ainda amplamente vinculadas ao "mundo do crime", através de rituais realizados em delegacias de polícia e em becos e favelas do Rio de Janeiro, ao mesmo tempo em que a igreja é frequentada por legisladores do Executivo e Legislativo e participa, ainda, de eventos solenes da UPP. Guardadas as 
significativas diferenças nos modos de atuação da IURD de São Paulo e da ADUD do Rio de Janeiro, esta última parece operar com alguns elementos do diagrama da primeira, articulando religião / segurança / assistência / política partidária.

As "políticas do crime" aparecem com muita força no trabalho de Birman e Machado (2012). As autoras analisam, entre outros pontos, o projeto teológico, político e social da ADUD, "que participa dispositivos políticos-religiosos relacionados com o tratamento da violência na cidade" (Birman e Machado 2012:58). A análise se pauta pelas imagens da intervenção do pastor Marcos Pereira em uma reunião do tribunal do tráfico, e sua intervenção salvadora através da mediação divina do Espírito Santo. A mídia religiosa destaca a necessidade de salvar os moradores da periferia da morte física e redimi-los como filhos de Deus e, deste modo, participa dos dispositivos de criminalização dos pobres: afirma o crime e, ao mesmo tempo, valoriza os empreendimentos da salvação. A análise convida o leitor a olhar para "o modo evangélico de pensar a metrópole” (Birman e Machado 2012:63). As práticas do Estado e do crime estão presentes, já que, de um lado, o pastor se concebe como mandatário do poder divino que ajudaria o Estado a lidar com as populações que estão nos tribunais, nas prisões, nas delegacias, nas favelas e outras regiões periféricas, corrigindo suas falhas; e, de outro, os rituais de exorcismo "mimetizam o conjunto de práticas da violência: barulho de metralhadora, gritos, exclamações e ordens imperativas" (Birman e Machado 2012:62).

Ainda que os rituais que amparam os "resgates" das igrejas pentecostais e neopentecostais não sejam unívocos, como demonstram os casos da IURD e da ADUD, as relações entre ativismo religioso e ordenamentos da segurança parecem compor um cenário mais geral em que essas igrejas têm ganhado um papel cada vez mais importante no gerenciamento das tensões e conflitos nas periferias. Em São Paulo, a atuação da IURD nos presídios, na Fundação Casa e nos territórios periféricos, não parece estar apartada do cenário contemporâneo de "expansão do mundo do crime" (Feltran 2010, 2011a e 2012b) - que não significa o aumento ou a diminuição de homicídios e outras taxas de criminalidade (que amparam a "Guerra de combate ao crime"), mas que denota a ampliação do "marco discursivo do crime" e as disputas, nas quais se envolvem várias organizações civis, pela legitimidade social e pelos critérios de subjetivação social e política. As igrejas neopentecostais são, certamente, uma modalidade de organização civil, entre outras, que desponta nesse projeto por meio de diversos tipos de ativismo religioso e de dispositivos encarnados na "Guerra entre Deus e o Diabo".

\section{Referências Bibliográficas}

ALMEIDA, Ronaldo. (2004), "Religiões na Metrópole Paulista". Revista Brasileira de Ciências Sociais, v.19, $\mathrm{n}$-56: $17-27$.

Nome / Fapesp.

(2009), A Igreja Universal e seus Demônios: um estudo etnográfico. São Paulo: Terceiro 
BIONDI, Karina. (2008), “A ética evangélica e o espírito do crime”. Trabalho apresentado no 26ํㅡeunião Brasileira de Antropologia. Porto Seguro, Bahia.

BIRMAN, Patricia. (2012), "Cruzadas pela Paz: práticas religiosas e projetos seculares relacionados à questão da violência no Rio de Janeiro”. Religião e Sociedade, v. 32, n. 1: 209-226.

BIRMAN, Patricia e MACHADO, Carly. (2012), "A violência dos justos: evangélicos, mídia e periferias da metrópole”. Revista Brasileira de Ciências Sociais, v. 27, n. 80: 55-70.

BIRMAN, Patricia e LEITE, Márcia Pereira (orgs.). (2004), Um mural para a dor: movimentos cívico religiosos por justiça e paz. Brasília: Ed. UFRGS.

CORTÊS, Mariana. (2007), O bandido que virou pregador: a conversão de criminosos ao pentecostalismo e suas carreiras de pregadores. São Paulo: Aderaldo \& Rothschil/ANPOCS.

DAS, Veena. (1999), "Fronteiras, violência e o trabalho do tempo". Revista Brasileira de Ciências Sociais, v. 14 , n. $40: 31-42$. California Press.

. (2007), Life and words: Violence and the descent into de ordinary. Berkeley: University of

ELIAS, Norbert. (1993), O processo civilizador. Formação do Estado e civilização. Rio de Janeiro: Jorge Zahar Ed., vol. 2.

FELTRAN, Gabriel. (2010), "Periferias, direito e diferença: notas de uma etnografia urbana”. Revistas de Antropologia, v. 53, n. 2: 565-610.

Editora Unesp/CEM. (2011a), Fronteiras de tensão: política e violência nas periferias de São Paulo. São Paulo: . (2011b), "Transformações sociais e políticas nas periferias de São Paulo”. In: L. Kowarick e E. Marques (orgs). São Paulo: novos percursos e atores. São Paulo: Editora 34/CEM.

FOUCAULT, Michel. (2002), Em defesa da sociedade. São Paulo: Martins Fontes.

FROMM, Deborah. (2014), "Deus e o Diabo na terra do crack". Trabalho apresentado no NEU - Núcleo de Etnografia Urbanas/CEBRAP. São Paulo.

GALDEANO, Ana Paula. (2009), Para falar em nome da segurança: o que pensam, querem e fazem os representantes dos Conselhos Comunitários de Segurança. Campinas: Tese de Doutorado em Ciências Sociais, Unicamp.

. (2012), "A gestão social da violência: de como ativistas de direitos humanos, líderes de associação de bairro e evangélicos se mobilizam”. In: N. Vieira da Cunha e G. Gabriel de Santis (orgs.). Sobre periferias: novos conflitos no Brasil contemporâneo. Rio de Janeiro: Editora Lamparina/FAPERJ.

. (2013a), "Voz e silêncio: os sentidos da violência no Conselho Comunitário de Segurança Pública”. Contemporânea - Revista de Sociologia da UFSCar, v. 3, n. 2: 335-357.

(2013b), "Gestion sociale de la violence dans une banlieue de São Paulo. Trois logiques d'engagement citoyen”. Brésil(s) - Sciences Humaines et Sociales, n. 4: 169-192.

GURZA LAVALLE, Adrian; CASTELLO, Gabriela e BICHIR, Renata M. (2007), "Redes, capacidade de ação na Sociedade: o caso de São Paulo - Brasil”. Redes. Revista Hispanica para el Análisis de Redes Sociales, vol. 12, nº. 6: 1-38.

HARDT, Michal e NEGRI, Antônio. (2001), Império. São Paulo: Record.

HARVEY, David. (2012), Condição pós-moderna. São Paulo: Loyola, 22a ed.

LANDIM, Leilah. (2012), "Organizações civis no Rio de Janeiro e suas periferias: novas cartografias?". In: N. Vieira da Cunha e G. de Santis Feltran (orgs.). Sobre periferias: novos conflitos no Brasil contemporâneo. Rio de Janeiro: Lamparina/FAPERJ.

LEITE, Márcia. (2012), "Da 'metáfora da guerra' ao projeto de 'pacificação': favelas e políticas de segurança pública no Rio de Janeiro”. Revista Brasileira de Segurança Pública, vol. 2, no. 2: 374-389.

. (2013), "La favela et laville: de la production des 'margens' à Rio de Janeiro". Brésil(s) - Sciences Humaines et Sociales, n. 3: 109-28.

MACHADO, Carly. (2013), "A igreja ajuda a UPP, e a UPP ajuda a igreja: reflexões sobre pacificação, religião e política a partir de uma igreja Assembleia de Deus na Baixada Fluminense". Trabalho apresentado no $37^{\circ}$ Encontro Anual da ANPOCS. Águas de Lindóia, São Paulo. 
MACHADO DA SILVA, Luís Antônio. (1993), "Violência urbana: representação de uma ordem social". Cadernos de Sociologia, vol. 4: 145-155.

. (2004), "Sociabilidade violenta: uma dificuldade a mais para a ação coletiva nas favelas". In: L. A. Machado da Silva et alli. Rio: a democracia vista de baixo. Rio de Janeiro: IBASE.

MAFRA, Clara. (1998), "Drogas e símbolos: redes de solidariedade em contextos de violência”. In: M. Alvito e A. Zaluar (orgs). Um século de favela. Rio de Janeiro: Editora FGV.

MAFRA, Clara; SWATOWISKI, Cláudia e SAMPAIO, Camila. (2012), "O projeto pastoral de Edir Macedo: uma igreja benevolente para indivíduos ambiciosos?". Revista Brasileira de Ciências Sociais, vol. 27, n-78: 81-96.

MARQUES, Eduardo (org.). (2012), Redes Sociais no Brasil. Sociabilidade, organizações civis e políticas públicas. Belo Horizonte: Fino Traço.

MARIANO, Ricardo. (1996), "Os neopentecostais e a Teologia da Prosperidade”. Revistas Novos Estudos CEBRAP, nㅇ 44: 24-44.

MISSE, Michel. (1999), "Crime urbano, sociabilidade violenta e ordem legítima: comentários

sobre as hipóteses de Machado da Silva”. Disponível em < http://www.necvu.

ifcs.ufrj.br/publicacoes/textos_download.asp> Acesso em 22/07/2014.

MOREIRA, Fábio Mallart. (20̄11), Cadeiras dominadas: dinâmicas de uma instituição em trajetórias de jovens internos. São Paulo: Dissertação de Mestrado em Antropologia Social, USP.

ROSAS, Nina. (2013), “'Amostra grátis' da prosperidade: ações de assistência na Igreja Universal e o caso de Minas". In: N. Vieira da Cunha e G. de Santis Feltran (orgs.). Sobre periferias: novos conflitos no Brasil contemporâneo. Rio de Janeiro: Lamparina/FAPERJ.

RUI, Taniele. (2012), Corpos abjetos: etnografias em cenários de uso e comércio de crack. Campinas: Tese de Doutorado, Unicamp.

. (2013a), "Fronteiras, espaços e usos do crack". In: N. Vieira da Cunha e G. de Santis Feltran (orgs.). Sobre periferias: novos conflitos no Brasil contemporâneo. Rio de Janeiro: Lamparina/FAPERJ.

. (2013b), "Depois da 'Operação Sufoco': sobre espetáculo policial, cobertura midiática e direitos na 'cracolândia' paulistana". Contemporânea - Revista de Sociologia da UFSCar, v.3, no 3: 287-310.

SOARES, Barbara Musumeci; MOURA, Tatiana; AFONSO, Carla (orgs.). (2009), Auto de resistência: relatos de familiares de vítimas da violência armada. Rio de Janeiro: 7Letras.

TATAGIBA, Luciana e BLIKSTAD, Karin. (2011), “'Como se fosse uma eleição para vereador': dinâmicas participativas e disputas partidárias na cidade de São Paulo”. Lua Nova, n. 84: 353-364.

TAUSSIG, Michael. (1997), The magic of the State. New York: Routledge.

TELLES, Vera da Silva. (2006), "Introdução" e "Debates: a cidade como questão". In: V. da Silva Telles e R. Cabanes (orgs). Nas Tramas da Cidade: trajetórias urbanas e seus territórios. São Paulo: Associação Editorial Humanitas.

VEYNE, Paul. (1982), Como se escreve a história. Foucault revoluciona a história. Brasília: Editora Universidade de Brasília.

VITAL CUNHA, Christina. (2008), "Traficantes evangélicos: novas formas de experimentação do sagrado em favelas cariocas". Plural, vol.15: 23-46.

VIANNA, Adriana e FARIAS, Juliana. (2011), "A guerra das mães: dor e política em situações de violência institucional".Cadernos Pagú, no 37: 79-116.

ZALUAR, Alba. (1998), "Crime, medo e política”. In: M. Alvito e A. Zaluar (orgs). Um século de favela. Rio de Janeiro: Editora FGV.

\section{Notas}

${ }^{1}$ Este trabalho é uma versão modificada do paper apresentado no Simpósio Temático "Sobre periferias: 
Religião e Sociedade, Rio de Janeiro, 34(1): 38-60, 2014

novos conflitos no espaço público", ocorrido durante o $37^{\circ}$ Encontro Anual da ANPOCS. A pesquisa de campo que deu origem a este artigo foi realizada entre 2006-2012, e é resultado de pesquisas de doutorado e pós-doutorado que contaram com o apoio da Fundação de Amparo à Pesquisa do Estado de São Paulo (FAPESP). Agradeço o coletivo de pesquisadores do Núcleo de Etnografias Urbanas (NEU/CEBRAP) - Ronaldo Almeida, Gabriel de SantisFeltran, Taniele Rui, Fábio Mallart Moreira, Paulo Malvasi, Maurício Fiori, Isabel Georges e Vagner Marques - pelas leituras e debates da primeira versão deste artigo.

2 Utilizo aspas para demarcar noções que implicam em representações sociais e expressões êmicas de uso corrente nas cidades, tais como "violência", "crime" e "mundo do crime", "Guerra entre Deus e Diabo" e "Guerra de combate ao crime".

3 Para esta discussão ver Feltran (2011a). O argumento é que em meio a todas as transformações sociais e políticas, o equacionamento dos conflitos sociais, que figurou em torno da democracia e da luta por direitos nas décadas de 1970 e 1980, é deslocado. A "violência" e o "crime" aparecem, então, como referências centrais das falas públicas sobre as periferias.

4 Moreira (2011) utilizou as trajetórias como recurso metodológico para compreender o deslocamento do universo da Fundação Casa em São Paulo, desde a criação da Fundação Nacional do Bem-Estado Menor (FUNABEM) até a configuração das "cadeias dominadas". Amparado numa leitura elisiana e bourdiesiana, o autor mostra que as trajetórias são muito mais que meros casos individuais interessantes. Ao contrário, elas encarnam as próprias transformações estruturais. Nesse sentido, as trajetórias dizem respeito às posições dos atores nos espaços sociais, para lembrar a consagrada acepção de Bourdieu, mas também ao fato de que, como lembra Elias, as mudanças na estrutura da sociedade correspondem a mudanças na estrutura da personalidade (Elias 1993). A relação entre estrutura e agência que se pode decantar da obra do autor está expressa em várias passagens d'O processo civilizador, como a que segue: "A agência controladora que se forma como parte da estrutura da personalidade do indivíduo corresponde à agência controladora que se forma na sociedade em geral" (Elias 1993:201)

5 A "expansão do mundo do crime" não pretende dar conta do maior ou menor grau de violência utilizada pelo PCC (Primeiro Comando da Capital), tampouco sua influência no aumento ou na diminuição da criminalidade. Esta categoria tem sido empregada para se referir "A maior amplitude de circulação (...) de um marco discursivo do crime, que passa a ocupar espaço de legitimação nas sociabilidades locais, especialmente entre jovens, ainda que não seja nem dominante nem hegemônico" (Feltran 2011b:315). Como afirma o autor: "Não se afirma aqui que o 'mundo do crime' se espraia indistintamente pelo tecido social das periferias, manchando o tecido social, sem que os jovens dali sejam ou estejam se tornando bandidos; a questão é outra: trata-se de um universo de relações em disputa pela legitimidade social, pelos critérios de subjetivação social e política, que trava relações tensas (e intensas) com uma série de outras instâncias sociais mais tradicionais" (Feltran op. cit.:364).

6 Tomar "a cidade como plano de referência" (Telles 2006) tem sido um dos aportes analíticos do coletivo de pesquisadores do NEU (Núcleo de Estudos em Etnografia Urbana)/CEBRAP, coordenado pelo professor Ronaldo Almeida. Trata-se, como afirma Paul Veyne, de levar em conta que as narrações devem explicar processos mais amplos: “(...) o que se denomina explicação não é mais que a maneira da narração se organizar em uma trama compreensível” (Veyne 1982:51).

7 Como afirma Vera da Silva Telles: “(...) os programas sociais se multiplicam pelas periferias afora e, entorno deles, vão se proliferando, por todos os cantos, associações ditas comunitárias que tratam de se converter à lógica gestionária do chamado empreendedorismo social, se credenciar como "parcerias" dos gestores públicos locais e disputar recursos nas fundações privadas (...) e agências multilaterais, isso em interação com miríades de práticas associativas e ao lado dos movimentos de moradia e suas articulações políticas, partidos e seus agenciamentos locais, igrejas evangélicas (também proliferantes) e suas comunidades de fiéis e, claro, a quase onipresença de organizações não governamentais vinculadas a circuitos e redes de natureza diversa e extensão variada. É um feixe de mediações em escalas variadas que desenha um mundo social mil anos luz de distância das imagens de desolação das periferias de trinta anos atrás, mas também perpassado por clientelismo e reivindicações do "direito à cidade", 
convergências e disputas, práticas solidárias e acertos (ou desacertos) com máfias locais e o tráfico de drogas" (Telles 2006:12).

8 Esses autores abordam o caráter polissêmico da "violência" e a importância de tratá-la não como um conceito, mas como um objeto a ser investigado. Por esse motivo, opto por grafar a palavra violência sempre entre aspas.

9 Desenvolvi análises sobre as dinâmicas e discursos dos conselhos em trabalhos anteriores (Galdeano 2009 e 2013a).

${ }^{10}$ Entrevista realizada em setembro de 2011. Os demais depoimentos de José, que aparecem entre aspas ao longo do texto, foram extraídos desta mesma entrevista realizada em 2011.

${ }^{11}$ Almeida (2009) mapeou a localização dos templos da IURD e de outras igrejas em São Paulo, traçando suas características espaciais. Entre elas, a proximidade de grandes avenidas.

${ }^{12}$ Como pretendo deixar claro mais adiante, esse ativismo evangélico na área da violência envolve uma série de outras mediações que não se limitam às relações com os partidos políticos. Birman e Machado (2012), por exemplo, analisam o novo protagonismo político-religioso das igrejas evangélicas a partir da discussão da atuação de um pastor da Assembleia de Deus dos Últimos Dias no resgate de um jovem ameaçado de execução pelo tribunal do tráfico.

${ }^{13}$ No Rio de Janeiro são sete (7) vereadores. Ver: http://noticias.gospelmais.com.br/rio-sao-paulo-elegemjuntos-18-vereadores-evangelicos-veja-lista-43727.html. Acesso em agosto de 2013.

14 São eles: Coronel Telhada (PSDB) e o ex-deputado estadual Conte Lopes (PTB). Jornal O Estado de São Paulo, disponível em http://www.estadao.com.br/noticias/politica,camara-de-sp-vai-ter-dois-expms-da-rota-e-oito-evangelicos-,942041,0.htm Acesso em agosto de 2013

${ }_{15}$ Ver: http://olharcristao.blogspot.com.br/2012/10/sao-paulo-elege-12-vereadores.html Acesso em agosto de 2013

${ }^{16}$ Ver: http://iurdnafundacaocasa.blogspot.com.br/2012/10/vereador-atilio-francisco-deu.html Acesso em agosto de 2013

${ }^{17}$ Nas palavras do autor: "Portanto, o racismo está ligado ao funcionamento de um Estado que é obrigado a utilizar a raça para exercer seu poder soberano. A justaposição, ou melhor, o funcionamento, através do biopoder, do velho poder soberano do direito de morte implica o funcionamento, a introdução e a ativação do racismo. E aí, creio eu, que ele efetivamente se enraíza" (Foucault 2002:209).

${ }^{18}$ Em um dos vídeos de culto da Igreja Batista, disponível no youtube, é possível visualizar jovens vestidos com roupas do exército marchando até o púlpito, acompanhados de exclamações de "Glória a Deus! Aleluia!" por parte dos fiéis, enquanto a pastora, vestida de camiseta camuflada, pede que os jovens teatralizem uma sequência de "marcha[s] para o Senhor".

Recebido em março de 2014. Aprovado em maio de 2014.

Ana Paula Galdeano (anapaula.galdeano@gmail.com)

Doutora em Ciências Sociais pela Universidade Estadual de Campinas (UNICAMP), com pós-doutorado em Sociologia Urbana pelo Centro de Estudos da Metrópole (CEM), vinculado ao Centro Brasileiro de Análise e Planejamento (CEBRAP). Atualmente é pesquisadora associada do CEBRAP e integrante do Núcleo de Estudos em Etnografias Urbanas (NEU/CEBRAP). 


\section{Resumo:}

\section{Salmo 127, versículo 1: ativismo religioso e ordenamentos da segurança em uma periferia de São Paulo}

Este artigo explora algumas relações entre ativismo evangélico e "violência". Mais especificamente, discute o protagonismo político-religioso de um fiel da IURD, e da própria igreja, nos conflitos relativos à "violência". Seguindo a trajetória de José, argumento que o diagrama religião - empreendedorismo - segurança - política partidária e assistência contribui para sua atuação como ordenador da segurança no gerenciamento das tensões e conflitos nas periferias. As redes de José e uma etnografia de um culto da IURD são mobilizadas para indicar as performances miméticas do poder do Estado, as relações entre o secular e o religioso e a maneira como a "guerra justa" está no enfeixamento entre a "Guerra de combate ao crime" e a "Guerra entre Deus e o Diabo".

Palavras-chave: violência, religião, secularismo, periferias, Estado.

\section{Abstrac:}

Psalm 127, verse 1: religious activism and security management in the periphery of São Paulo

This article examines some relations between religious activism and "violence". More specifically, it discusses the political-religious protagonism of both José - a worshiper from IURD - and of the church it self with regard to conflicts related to "violence". While following the trajectory of José, I argue that the entanglement among religion, entrepreneurship, security and partisan politics contributes to his performance as a security agent on managing tensions and conflicts in peripheries. I look at José's networks and at an ethnography in to an Universal Church worship service in order to indicate the mimetic performances of the State power, the relation between secularism and religion as well as to locate the "just war" within the inter connections between the "waron crime" and the "war between God and Evil".

Keywords: violence, religion, secularism, peripheries, State. 